\title{
Using a landscape ecological perspective to analyze regime shifts in social-ecological systems: a case study on grassland degradation of the Tibetan Plateau
}

\author{
Li Li (iD) Fabian Ewald Fassnacht • Matthias Bürgi
}

Received: 27 June 2020/Accepted: 7 January 2021 / Published online: 1 February 2021

(C) The Author(s) 2021

\begin{abstract}
Context Landscape ecology thinking and social-ecological system (SES) thinking investigate human-environment relationships from the perspective of 'space' and 'system', respectively. To date, empirical landscape ecology studies attempting to understand SES complexities are rare.

Objectives Using the Tibetan pastoral landscape as an empirical example, we conceptualize the black-soil formation as SES regime shifts. We seek to illustrate the spatial patterns of black-soil formation in the
\end{abstract}

Supplementary Information The online version contains supplementary material available at https://doi.org/10.1007/ s10980-021-01191-0.

L. Li $(\bowtie)$

Department of Health and Environmental Sciences, Xi' an Jiaotong-Liverpool University, Chongwen Road 8,

Suzhou 215123, China

e-mail: li.li01@xjtlu.edu.cn

L. Li

Center for Nature and Conservation, School of Life Sciences, Peking University, Yiheyuan Road 5, 100871 Beijing, China

F. E. Fassnacht

Institute of Geography and Geoecology, Karlsruhe Institute of Technology, Kaiserstraße 12,

76131 Karlsruhe, Germany

M. Bürgi

Research Unit Landscape Dynamics, Swiss Federal Research Institute WSL, Zürcherstraße 111,

8903 Birmensdorf, Switzerland
Tibetan SES, and to reveal their underlying ecological processes.

Methods We conducted interdisciplinary research in a Tibetan pastoral village. We obtained quantitative data on historical land-use intensity (LUI) and the associated management narratives. Landsat-based NDVI time series were used to derive a grassland productivity proxy and to reconstruct the process leading to the upscaling of the regime shift of degradation.

Results Important SES features, such as LUI, productivity and degradation risk are heterogeneously distributed in space. Land-use intensification at farm-scales in the 1990s increased landscape-scale degradation risks. Eventually the regime shift of degradation scaled up from the plot level to the landscape level in the 2010s. The time lag was related to the gradual invasion of a native burrowing animal, the plateau pika, which inhabits low-vegetation height pastures.

Conclusions Our study shows that landscape ecology thinking provides an important spatial perspective to understanding SES complexities. The finding that unfavorable SES regime shifts are strongly linked across spatial scales implies that an 'entry point' into an adaptive management circle should be initiated when local-scale regime shifts are perceived and interpreted as early warning signals.

Keywords Black-soil degradation - Carrying capacity $\cdot$ Interdisciplinary research $\cdot$ Landsat $\cdot$ Landuse intensity · NDVI · Threshold · Complex system 


\section{Introduction}

Landscape ecology thinking and social-ecological system (SES) thinking conceptualize the humanenvironment relationship from distinct perspectives. Landscape ecology puts 'space' at the center of its study, and investigates the interactions between human activities and ecological processes therein (Pickett and Cadenasso 1995; Turner 1989; Wu and Hobbs 2002). SES thinking takes a 'systems' approach to examine interrelationships among components in both social and ecological sub-systems (Berkes and Folke 1998; Ostrom 2009). The SES approach was further conceptualized as complex adaptive systems that contain feedback loops and nonlinearities (Berkes et al. 2008; Folke et al. 2005; Levin et al. 2013; Liu et al. 2007). It has been discussed that interdisciplinary frameworks should be developed to incorporate landscape ecology's spatial perspective into sustainability studies of the 'system thinking' school (Cumming et al. 2013). However, to date, genuine landscape ecology studies addressing complexity of SES remain scarce.

One notable example of SESs' complexity is that they can undergo large-scale, abrupt, and persistent changes from one stable state to another, recognized as a 'regime shift' (Folke et al. 2004; Scheffer et al. 2001). In regime shifts, incremental changes or external shock in anthropogenic and/or natural domains push a system to switch dominant feedbacks and drive the system into a new regime (Biggs et al. 2009). Drastic SES regime shifts can cause catastrophic events in ecosystems which may appear surprising to people since they can occur as drastic changes after long periods of stability. However, studies aiming to develop concept frameworks to avoid unfavorable regime shifts face several challenges. Drawing clear-cut boundaries of SESs isn't always straightforward, feedbacks can be confused with drivers, and analyses on feedback processes are mostly descriptive instead of quantitative. Regime shifts are often identified in retrospect and timely identification of early warning signals remains difficult (Lindenmayer et al. 2011). All of these issues hinder the utility of SESs as heuristic models to predict system change trajectories (Biggs et al. 2018). The regime shift concept has been criticized that it might be more of a communicative notion than an anatical one (Kull et al. 2018).
Documented SES regime shifts are frequently related to critical transitions in human land-use practices, where land-use changes result in unexpected and major shifts in ecosystems (Biggs et al. 2018; Ramankutty and Coomes 2016). The impact of landuse changes on landscape patterns and processes is one of the fundamental questions for landscape ecology research. Recent advancements of concept and methodology in landscape ecology pave the way for in-depth studies investigating system complexity and nonlinearity in the spatial domain. For instance, landuse intensity has been parametrized as a quantitative agent to link social and ecological systems from plot to landscape scales (Bürgi et al. 2014, 2015). The legacy effect has been elaborated to explain the time lag which can be frequently observed between the start of land-use changes until the clear notability of their effects on the landscape (Bürgi et al. 2016; Li et al. 2017). Development in remote sensing methods, e.g., participatory GIS, facilitates interdisciplinary studies to link people and nature at matching scales where relevant interactions take place (Brown and Kytta 2014; Fagerholm et al. 2012; Hopping et al. 2018) and may also provide informative data about past conditions not surveyed in the field ( $\mathrm{Li}$ et al. 2017).

One example of human land-use induced regime shift is the formation of black-soil land on the Tibetan Plateau (Harris 2010; Li et al. 2017; Wang et al. 2015). Black-soil formation is a grassland degradation process where vegetation cover declines steadily and rapidly with the loss of perennial sedges and grasses, which eventually changes the alpine meadow to a stable unvegetated bare-soil state (Xiao et al. 1982). In the Sanjiangyuan region of Qinghai province alone, the area of black-soil land has reached $47,000 \mathrm{~km}^{2}$ (Shang et al. 2018). In such black-soil areas, the dense-root networks formed by Kobresia species are totally destroyed with over $60 \%$ soil organic carbon getting lost (Shang et al. 2018), leaving the bare soil prone to water and wind erosion (Miehe et al. 2019). The formation of black-soil land has caused Tibetan pastoralists a great deal of concern with their livelihood being threatened (Wu et al. 2015). There is a confusion regarding the causality of the unprecedented rapid and large-scale degradation, and local people perceive the degradation as a surprise ( $\mathrm{Li}$ et al. 2017; Liu et al. 2007). In China's grassland restoration programs for the Plateau, plateau pikas (Ochotona curzoniae) have been recognized as one of the direct 
causes of grassland degradation and were targeted for eradication (Xin 2008). However, such claim has been contested among the scientific community, who attributes the colonization of plateau pikas as the end stage of an ongoing grassland degradation driven by a variety of factors (Harris 2010; Smith and Foggin 1999). In the dispersal of a source population, the plateau pika usually prefers a low-grass-height habitat where predators can be visually detected (Sun et al. 2015; Wang et al. 2004). Such habitat can be created by locally intensified livestock foraging and trampling due to reduced pastoral mobility resulting from pastoral management changes in the 1980s ( $\mathrm{Li}$ et al. 2017), i.e., there is a legacy effect between land-use changes in the social system and their ecological consequences.

Using the degradation of Tibetan grassland as a case study, we aim to demonstrate how SES regime shifts can be investigated in space. The black-soil areas are spatially stable, and sites where the degradation has occurred can therefore be mapped and delineated in GIS. The onset of the regime shift can be identified with time series of remotely sensed images and linked to factors driving the state change in the SESs, e.g., land-use intensification. Analyzing the development of those spatial patterns enables us to scrutinize the socio-ecological processes underlying the regime shift. The research aims to answer the following questions: 1 . What are the spatial features of black-soil areas formed in the Tibetan grassland? 2. What is the role of the plateau pika in the degradation process? 3. How can we identify early warning signals in order to prevent black-soil formation? 4 . What are the management implications for Tibetan pastoralists and policy makers? Representing regime shifts in space makes it possible to apply concepts and methods from landscape ecology to SES analyses, by e.g. mapping high-risk sites for degradation and analyzing trajectories of the SES transition in time series. We will conclude with some considerations how landscape ecology can contribute to SES research.

\section{Methods}

Conceptualizing the black-soil formation as an SES regime shift

From the SES perspective, the formation of black-soil areas is driven by feedback changes between land-use intensity (LUI) and grassland forage productivity in the rangeland SES, where LUI increases continuously to initiate a positive feedback between livestock grazing and the dispersal of plateau pika to trigger a regime shift of black-soil formation. Here, plateau pika is one of the main drivers steering the underlying ecological process, and the impact of pika is most prominent at the plot scale. The black-soil formation takes place after increasing LUI surpasses productivity of the plot (Fig. 1). This decoupling of LUI and productivity eventually changes the system feedback - the regrowth of plant biomass doesn't keep up with the biomass consumed by both livestock and pika. Thus, we propose to conceptualize the difference between productivity and LUI as the ecosystem's degradation risk: When the productivity-LUI difference is small, the grassland has a higher risk to degradation. In the stable phase of SES (Fig. 1 P1P2), LUI-productivity feedbacks remain coupled. At time point $\mathrm{P} 2$, the SES feedback change starts as the mean value of LUI increases while productivity remains unchanged. The onset of a degradation regime shift occurs earlier when degradation risk is higher (Fig. 1, P3) and later when degradation risk is lower (Fig. 1, P4). With higher degradation risk, the time window left for adjusting the LUI feedback to productivity is narrower (Fig. 1, P2-P3). In comparison, when degradation risk is low, the adaptation time window is wider (Fig. 1, P2-P4).

Interdisciplinary research framework

In the investigation of the Tibetan rangeland SES's regime shift, we adopted interdisciplinary approaches for data collection and analysis (Fig. 2). Ecological data, such as the productivity proxy, historical NDVI changes, the pika-vegetation relationship and vegetation cover and compositional data, were obtained from remote sensing time series analysis and field sampling. Land-use and land-management data from the social system were derived using oral history interviews and participatory GIS. The regime shift of degradation and 


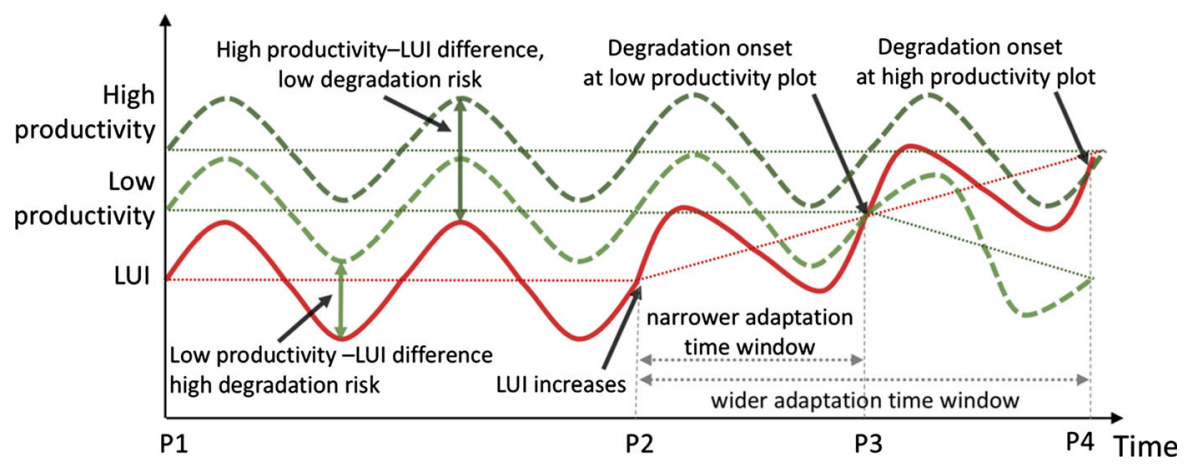

Fig. 1 The regime shift of the Tibetan grassland SES at the plot scale is conceptualized as an increase in LUI such that it surpasses productivity to trigger the formation of black-soil area. In the stable phase of SES (P1-P2), LUI-productivity feedbacks remain coupled. LUI is tuned to adapt to productivity, which presents a wave pattern due to temporal fluctuations, e.g. seasons. Driving forces such as land-use intensification starts the state change at time point $\mathrm{P} 2$, where the mean value of LUI increases while productivity remains unchanged. The onset of a degradation is marked by the crossing of LUI above productivity, which occurs earlier (at time point P3) if productivity is lower, and later (at time point $\mathrm{P} 4$ ) if productivity is higher. The degradation results in the decline of the productivity of the plot. The difference between productivity and LUI defines the plot's degradation risk. When degradation risk is high, the adaptation time window (P2-P3) left for a negative LUI feedback on productivity is narrower. In comparison, when degradation risk is low, the adaptation time window is wider (P2-P4)

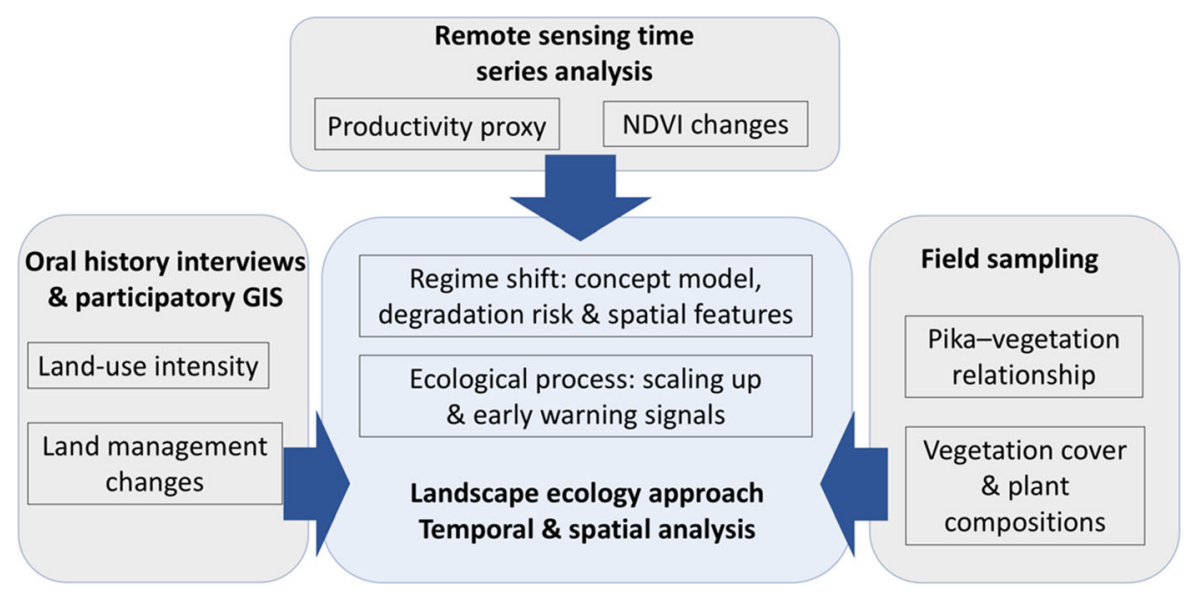

Fig. 2 Interdisciplinary research framework integrating remote sensing, oral history interviews and ecological field sampling for data collection and analysis to investigate the black-soil formation of the Tibetan rangeland and its underlying mechanisms

its underlying ecological mechanism were studied with the landscape approach, e.g., mapping degradation risk and the black-soil areas in their spatial context, illustrating and explaining their patterns in space, and assessing how the patterns have changed over time.

Study area

The case study village Karma (alias name used) is a traditional pastoral village covering a total area of 137 $\mathrm{km}^{2}$. Located in the Eastern Tibetan Plateau
(Supplementary Fig. S1), it has an average elevation of $4000 \mathrm{~m}$ a.s.l. The dominant vegetation type in Karma is alpine meadow with Kobresia pygmaea being the constructive species. As a base for transhumance with yak, the village is separated into $50 \mathrm{~km}^{2}$ of winter rangeland (used for eight months, from late October to late June) and $87 \mathrm{~km}^{2}$ of summer pasture (used for four months, from late June to late October). There is no hay meadow in Karma, and yak stay outdoors foraging through the winter months since the snow cover remains rather thin, with precipitation from November to April contributing only 
approximately $10 \%$ of the annual total (Guoluo Overview Editors' Group 2009). In the mid-2000s, grassland degradation started to expand in the winter rangeland, resulting in the formation of black-soil land described above. Local nomads perceive 'the arrival of plateau pikas' as the major cause of the degradation (Li et al. 2017).

Land-use management interviews and farm-scale LUI calculations

We combined oral history interviews and participatory GIS (PGIS) interviews to obtain historical land-use information. In land-change studies, oral history has been increasingly used to acquire information about fine-scale historical land use (Gimmi and Bürgi 2007; Santana-Cordero et al. 2016) or to validate or complement literature records or remotely sensed data (Gagnon and Berteaux 2009; Pinto and Partidario 2012). Community participatory mapping or PGIS has been rapidly evolving to promote the sharing of local people's knowledge in scientific research and rural planning (Brown and Kytta 2014). The increasing applications of PGIS in landscape studies are making use of the fact that community stakeholders are capable of recognizing and mapping their activities in the landscape, pointing out spaces and objects of cultural value, and locating significant changes in the environment (Fagerholm et al. 2012).

In our study, the interviews were conducted during the field seasons of 2014 and 2015, when we made 66 interviews with 24 key informants. As input for the interviews, we used the high-resolution unmanned aerial vehicle (UAV) images of the village to indicate the local landmarks and help the villagers with orientation. We asked four key informants, who used to be the leaders or accountants of the village, to draw household grazing boundaries corresponding to the time points of 1985 and 1994 (i.e., before the ecosystem regime shift took place), and of 2015, after the regime shift had been initiated. In 2016, we printed the boundary maps and organized one village representative meeting to verify the boundaries of the village and of each family's land. In 2018 and 2019, we revisited Karma to record the state of black-soil areas and interview the village leaders about their adaptative actions. Both the interviews and the community representative meetings were conducted in the local Tibetan dialect with the assistance of
Tibetan-Chinese translators. Reliable household-level records of livestock numbers are scarce for the study area; thus, in data analysis we used high-confidence data from three time points: 1 . The year 1985, when the livestock was evenly distributed among villagers. The village members and the local agricultural bureau provided consistent records of the livestock numbers. 2. The year 1994, when winter pastures were divided into household shares. The Jikdril County agricultural bureau conducted a demographic and livestock census. We obtained the unpublished data and confirmed the numbers with the former village accountant and other elder nomads. 3. For the year 2015, the nomads were hesitant to disclose the real livestock number of the current year. We hence repeatedly counted livestock numbers in the pastures in the summers of 2014 and 2015, and we used the highest counted value as a proxy for the true number.

Based on the livestock numbers and the area of the pastures, we calculated LUI for each pasture at the time point 1985, 1994 and 2015. Student's t-test was performed to detect LUI differences among the years. LUI is measured by calculating household-level standardized livestock numbers per hectare during the grazing period of the year (Bürgi et al. 2015). The LUI at the farm scale contains three components: numbers of livestock using the pasture $(\mathrm{N})$, pasture size (S), and months of use during the year $(\mathrm{T})$.

LUI $=\frac{N}{S} \times \frac{T}{12}$

Vegetation transects and plateau pika burrow counts

To understand the role of plateau pika in the degradation of rangeland in Karma, we tested the relationship between pika density and pasture status in terms of vegetation height and species composition. In 2014 we set up $7010 \mathrm{~m} \times 2 \mathrm{~m}$ grassland vegetation transects under the UAV covered area in the study region. To avoid the problem of pseudo-replication (Shang et al. 2018), we kept a minimum distance of $150 \mathrm{~m}$ between transects. We made five measurements of vegetation height along the central axis of each transect, at distances points of $0 \mathrm{~m}, 2 \mathrm{~m}, 5 \mathrm{~m}$, $8 \mathrm{~m}$ and $10 \mathrm{~m}$ from one edge. The height was measured by estimating vertical vegetation cover projected to a $50 \mathrm{~cm} \times 50 \mathrm{~cm}$ checkerboard. In each 
vegetation transect we estimated the ground coverages of unpalatable forb including poisonous weeds Stellera chamaejasme, Ajuga lupulina, Elsholtzia densa etc. (Shang et al. 2018; Song et al. 2008), as well as pioneer forbs colonizing black-soil land, including Hedinia tibetica, Microula sikkimensis, Microula tibetica.

All pika burrows were first counted in the 70 vegetation transects, and then we spread a thin layer of flour at the entrance of each burrow. Later the same day we returned to the marked burrows to check if there was any trace of pika activity on the flour layer. In this way we recorded the number of active pika burrows in each plot (Sun et al. 2015). Finally, we performed an ANOVA test to detect if there was any significant difference in pika burrows and active burrows among pastures of varied vegetation heights.

Measuring black-soil areas using unmanned aerial vehicles

From June to July 2014, we used three fixed-wing UAVs (eBees produced by senseFly) to quantitatively measure black-soil areas in the study area. The UAVs were equipped with a Canon IXUS 127HS camera which had a 16-MP true-color sensor. With 39 flights, we captured 5559 images which covered a total area of $45.8 \mathrm{~km}^{2}$. We processed the images with Photoscan Professional 1.1.6 (Agisoft). Based on high-resolution $(10 \mathrm{~cm}$ level) orthophotos produced, we manually identified and delineated black-soil areas at a scale of $150-\mathrm{m}$ radius. The $150-\mathrm{m}$ radius was selected as the scale at which variations of different land-cover types were distinguished in the study landscape (Fritz et al. 2018).

\section{Remote-sensing-based proxy for productivity}

A retrospective reconstruction of the grassland productivity is almost impossible if no corresponding field data are available. However, historical remote sensing data make it possible to estimate grassland productivity of the past using proxy variables such as vegetation indices. Here, we applied the Google Earth Engine (Gorelick et al. 2017) to calculate the $95^{\text {th }}$ percentile of NDVI values of all available Landsat 5, 7 and 8 images (Surface Reflectance Products) over the study area. This covers the period from 1986 to 2020 . We selected the $95^{\text {th }}$ percentile instead of the maximum NDVI values to account for data artefacts of unrealistically high NDVI values caused by preprocessing errors, which sometimes occur in the Landsat archives. NDVI is a general measure of the amount, density and vigor of vegetation. We assumed that the $95^{\text {th }}$ percentile of NDVI calculated for this 35-year time span mirrors the theoretical maximal amount of plant mass that a certain pasture can reach and that this relates to its productivity. The final productivity proxy based on NDVI had a $30 \mathrm{~m}$ pixel size. It should be noted, that while NDVI is a good proxy for general vegetation productivity it hardly captures species-related information. The latter is a relevant variable to estimate the available forage. In our case, an increase in NDVI could for example also be related to the increase of shrub cover in a pixel, which may be negatively related to the abundance of forage (Hopping et al. 2018). However, the encroachment of shrubs in the winter rangeland wasn't raised as a major concern by our interviewees.

Proxy for degradation risk

We defined degradation risk as the difference between LUI and productivity. A preliminary study showed that the degradation from vegetated grassland to black-soil land took place in Karma's winter rangeland after the year 2000 (Li et al. 2017). To understand the degradation risk pattern in space, we mapped farmscale degradation risk in 1985 and 1994, i.e., before the degradation took place. First, we normalized farmscale productivity proxies from 0 to 1 , separately for 17 pastures in 1985 and 20 pastures in 1994. Second, we pooled together LUIs measured for the 17 pastures in 1985 and the 20 in 1994, and normalized the 37 values from 0 to 1 . Then, we calculated the difference between the normalized productivity and normalized LUI for each pasture in 1985 and 1994, as a proxy for its risk to a regime shift of degradation.

Detecting the expansion of black-soil areas with remote sensing time series

To examine the spatio-temporal development of the degraded areas of Karma village, we prepared two more Landsat-based NDVI datasets using the Google Earth Engine. In the first dataset, we calculated the $95^{\text {th }}$ percentile of all available NDVI values for the four shorter periods 2000-2005, 2006-2010, 
2011-2015 and 2016-2020, and then we subtracted the NDVI-based productivity map described above (i.e., the 95th percentile NDVI value for the complete time series 1986-2020) from values in each of these four shorter periods. The resulting difference maps showed spatial patterns of how much the pastures deviated from their maximal productivity status in the four periods.

For the second dataset, we calculated annual maximum NDVI values for degrading and stable vegetation areas for the period between 1986 and 2020. For both degrading and stable areas, we randomly selected 40 Landsat pixels distributed over the winter rangeland of Karma. Degrading pastures were defined as pastures that had at least a 0.2 lower 95 th percentile NDVI value in the period 2016-2020 compared with values in the NDVI-based productivity map. Stable pastures were defined as all areas that showed no clear deviation from the productivity map in the 2015-2020 period. For each of the 80 pixels, we derived NDVI values from all available Landsat 5, 7 and 8 images to create a continuous (periodicity of a few days) time series using all available data. We then derived two mean time series from the 40 pixels per class (Supplementary Figs. S2, S3) and transformed the continuous mean time series into an annual maximum NDVI time series. Finally, we calculated a time series showing the differences between the stable and degrading areas.

\section{Results}

Land-use and pastoral management changes of Karma

In the mid-1980s, Karma village divided the collective livestock and its winter rangeland into individual household shares following the land reformation policy. Since the winter pastures on the eastern side of the valley are on average $100 \mathrm{~m}$ higher than those on the western side, Karma villagers decided to divide the rangeland such that pastures in the east are larger than those in the west. After the privatization in the 1980s, livestock numbers continued to rise until the 1990s. From 1985 to 1994, there was a substantial increase of LUIs in Karma: the stocking rate for the whole village had increased by $60 \%$, while the average size of winter pasture dropped by $20 \%$ due to further pasture divisions when new families were formed (Table 1), which both lead to the increase of LUIs.

One notable land management change in Karma is the use of permanent iron fences. Free iron fences were provided to Karma since 2004 to protect degraded grassland for resting and recovery. However, Karma villagers used the fences to designate their private pasture boundaries. When surplus fences were continually provided by the government, villagers started to fence up their autumn and spring pastures. In 2015, we mapped approximately 64,000 $\mathrm{m}$ fences in Karma's winter rangeland, i.e., $1200 \mathrm{~m}$ per household. Fences became popular among Karma also because they can replace the function of shepherd. With those permanent iron fences, Karma pastoralists considered no more need of a full-time herdsman. From 2004 onward, the installation of fences further reduced the mobility of pastoralism, pastures were further divided from 21 to 30 pieces with rigid boundaries (Table 1). It was mentioned in our interviews that due to the fences and in the absence of herdsmen, livestock foraging became more selective, which seemed to aggravate the unevenness of LUIs distribution within a pasture, resulting in plotscale LUI intensification where more palatable plants were present.

Spatial patterns of LUI, productivity and degradation risk proxies

Figure 3 shows the spatial distribution of the LUI proxy (range $0.44-5.17$ sheep unit/ha) and the productivity proxy (range 0.67-0.76) for Karma's winter rangeland in 1985 and 1994. The degradation risk of each pasture was measured as the normalized difference (range $0-1$ ) between the normalized LUI proxy and the normalized productivity proxy. T-test detected significant differences $(P<0.05)$ between mean LUI values of 1985 (1.27 sheep unit/ha) and 1994 (1.97 sheep unit/ha), i.e., land-use intensified in average by $55 \%$ in less than 10 years. LUI, productivity and degradation risk were heterogeneous in space and had incongruent distribution patterns. Land-use intensification during 1985-1994 increased landscape-scale degradation risk. At the farm scale, a reduced difference between productivity and LUI increased a pasture's degradation risk. 
Table 1 Historical demographic and economic data of Karma

\begin{tabular}{llllllllr}
\hline Year & $\begin{array}{l}\text { Household } \\
\text { No }\end{array}$ & Population & $\begin{array}{l}\text { Winter } \\
\text { Pasture } \\
\text { No }\end{array}$ & $\begin{array}{l}\text { Mean size of } \\
\text { Winter pastures } \\
\text { (ha) }\end{array}$ & $\begin{array}{l}\text { Summer } \\
\text { Pasture } \\
\text { No }\end{array}$ & $\begin{array}{l}\text { Mean size of } \\
\text { Summer pastures } \\
\text { (ha) }\end{array}$ & $\begin{array}{l}\text { Stocking } \\
\text { rate by } \\
\text { heads }\end{array}$ & $\begin{array}{l}\text { Stocking rate } \\
\text { by sheep units }\end{array}$ \\
\hline 1985 & 17 & 118 & 17 & 302 & 7 & 1248 & 2967 & 8008 \\
1994 & 21 & 135 & 20 & 240 & 7 & 1248 & 3756 & 12,811 \\
2015 & 53 & 214 & 30 & 212 & 13 & 672 & 1442 & 5870 \\
\hline
\end{tabular}

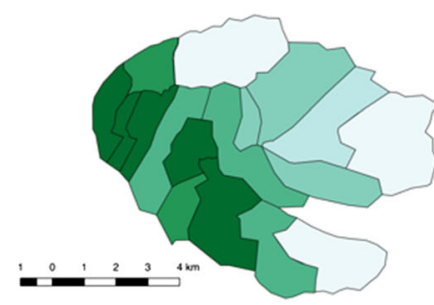

Productivity Proxy 1985

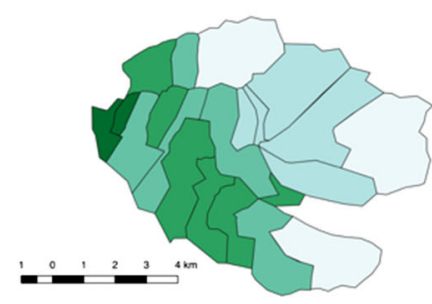

Productivity Proxy 1994

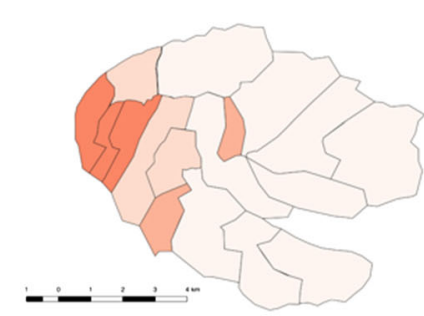

Land-use Intensity Proxy 1985

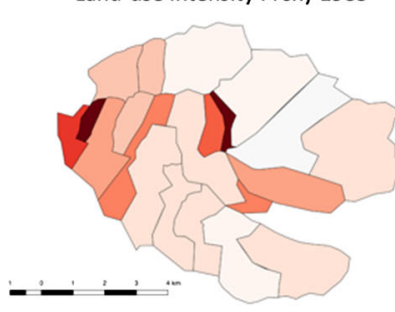

Land-use Intensity Proxy 1994

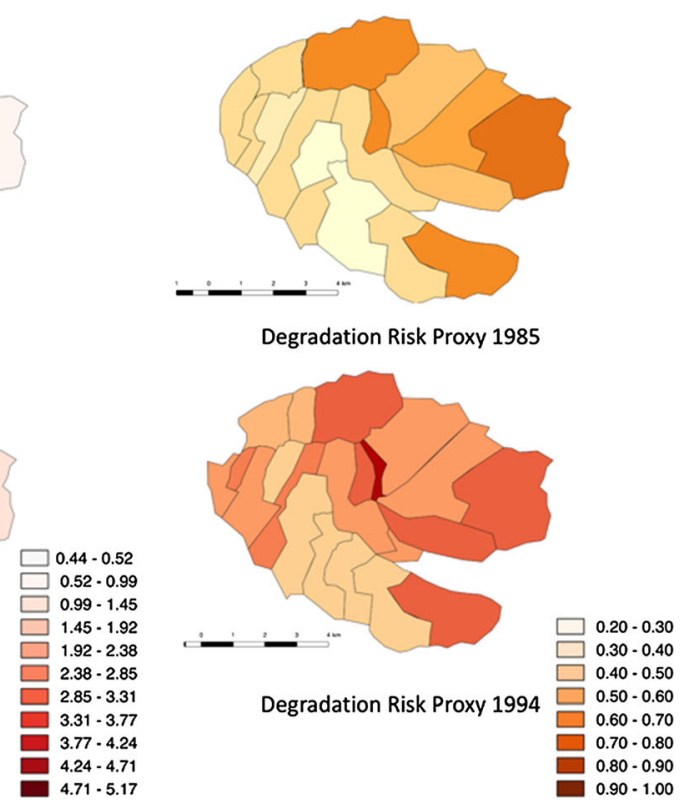

Fig. 3 Mapping proxies for winter rangeland land-use intensity (LUI, range 0.44-5.17 sheep unit/ha, note that LUI was annualized for the eight months of usage per year, i.e., the time coefficient of 0.67 was multiplied by the livestock number per area for the winter pastures) and productivity (range 0.67-0.76) of the village Karma in 1985 and 1994. Degradation risk for each household's pasture is measured by the difference (range

Scaling up of the degradation from plots to landscape

At the plot scale, we detected significantly higher pika densities in pastures with a low average vegetation height (Fig. 4a, b). Increasing black-soil coverage changes the plant composition from sedge and grass dominated alpine meadow to an increasing coverage of unpalatable forbs (Fig. 4c).

In Karma, the vegetation change time series demonstrated that the ecosystem regime shift first took place locally in 2006-2010 (Fig. 5b),
0-1) between normalized LUI and normalized productivity. LUI, productivity and degradation risk are all heterogeneously distributed in space, and their distributions are not congruent. Land-use intensification from 1985 to 1994 has generally increased the degradation risk of the village. However, pastures bearing higher degradation risk in 1994 are not always the ones with high LUI or low productivity

approximately ten years after the historical apex of LUI of the village was reached in the mid-1990s. The local-scale regime shift of high-coverage grassland transforming to black-soil areas expanded to the landscape scale in approximately ten years (Fig. 5d). When using 1994 as the reference year for evaluating degradation risk, pastures experiencing a farm-scale regime shift by 2020 had on average a $58 \%$ higher risk $(P<0.05)$ than non-degraded pastures. 


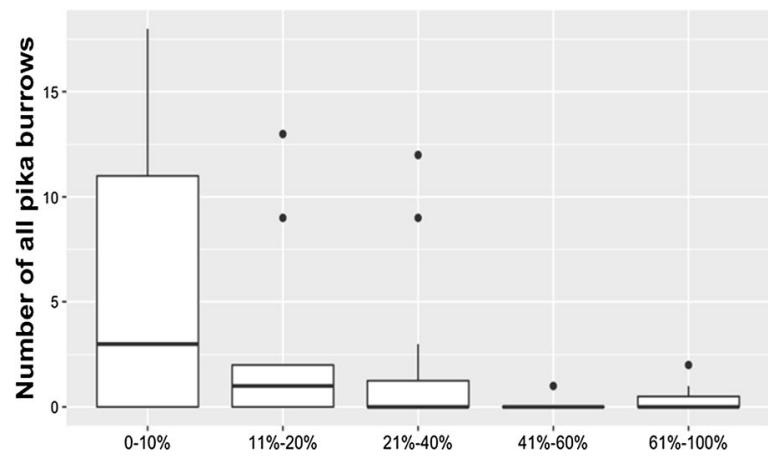

(a) Vertical vegetation coverage

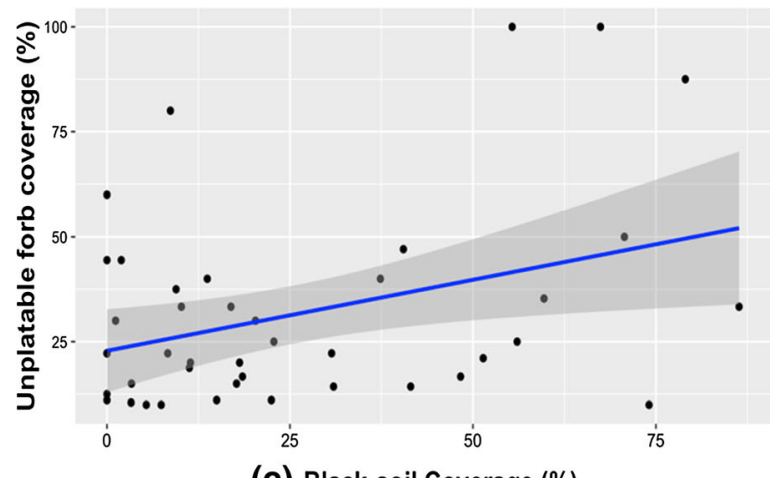

(c) Black-soil Coverage (\%)

Fig. 4 Plateau pika density in relation to vegetation height and plant compositional change with increasing black-soil areas. Numbers of both all plateau pika burrows (a) and active burrows (b) were significantly different among the five vegetation height groups (ANOVA test, $P<0.05$ ) in the plant transects, and both distinguished transects of $41 \%-60 \%$ vertical vegetation coverage (10 transects, ca. $20-30 \mathrm{~cm}$ height in average, $P<0.05)$

Time lags among the land-use changes, degradations and adaptations

In the regime shift of the Tibetan rangeland SES, there were two noticeable time lags: 1 . between the increasing of LUI (1985-1994, Fig. 3, Table 1) and the formation of black-soil land at the landscape scale (2016, Fig. 5c, d); 2. between the plot-scale regime shift which took place in 2006 (Fig. 5b) to the earliest collective adaptation of the Karma village in 2019.

Historical LUI data and NDVI time series identified critical transitioning time points in both the social and the ecological systems. Analysis of the historical data revealed that an increase of LUI started before 1994, increasing the degradation risk (Fig. 3). On remotely sensed images, black-soil formation was first detected

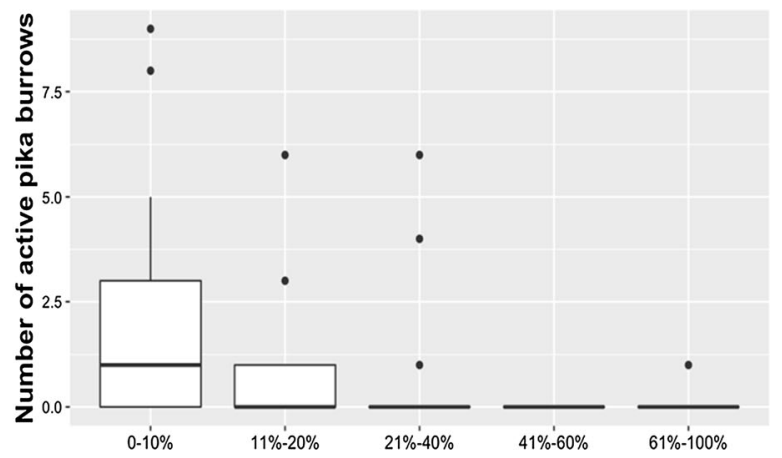

(b) Vertical vegetation coverage

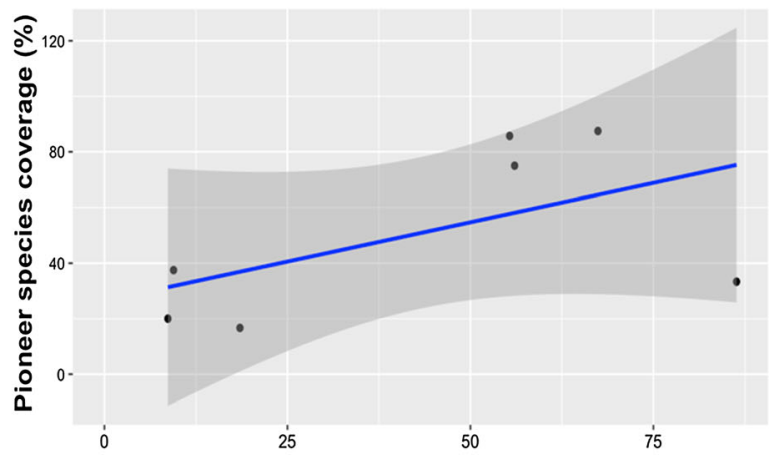

(d) Black-soil Coverage (\%)

from transects of $0-10 \%$ vertical vegetation coverage (22 transects, ca. $0-5 \mathrm{~cm}$ height in average, $P<0.05$ ). Increasing proportion of black-soil areas within the $150-\mathrm{m}$ radius increased the coverage of unpalatable forbs $\left(\mathbf{c}, P<0.05, \mathrm{R}^{2}=0.133\right)$ and black-soil pioneer species $\left(\mathbf{d}, P=0.187, \mathrm{R}^{2}=0.317\right)$ up to over $80 \%$ in the sampled transects $(\mathbf{d})$. Linear regression lines are fitted with $95 \%$ confidence limits

locally between 2006 and 2010 (Fig. 5b) and upscaled to the landscape scale around 2016 (Fig. 5d). Figure 6 shows the difference in mean maximum annual NDVI time series between selected black-soil areas and stable areas (Supplementary Fig. S2) from 1986 to 2019: the trend of increasing divergence began in 2006 and continued steadily until a local maximum was reached in 2016, then stabilized at a high level until the present. Drastic fluctuations in the 1980s were caused by a lack of available data rather than representing the vegetation dynamics of the rangeland. The original Landsat time series and time-gap interpolated time series plotting indicated consistent patterns (Supplementary Fig. S3).

It took over a decade for black-soil patches to expand and have an impact on Karma's community 
Fig. 5 Scaling-up process of black-soil formation from the local scale (2006-2010) to the landscape scale (2016-2020). Pastures that experienced a farm-scale regime shift from 2016 to 2020 had significantly higher $(P<0.05$, difference in mean $=0.21)$ degradation risk values that were measured in 1994 (the 1994 risk values were labelled for each pasture in all the four panels). The degraded pixels (markd in red) were identified as their deviation of the 95th percentile of all available NDVI values for the four shorter periods from their maximal productivity status in the four periods

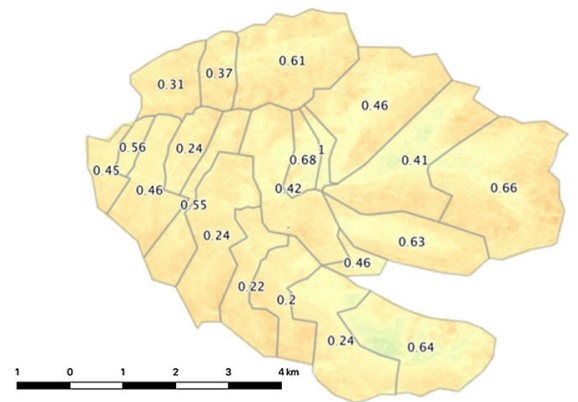

(a) Degradation 2001-2005

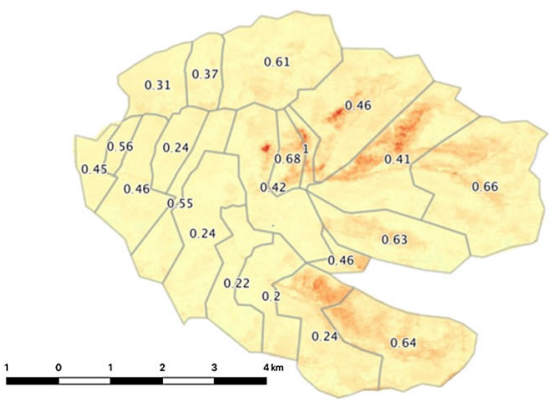

(c) Degradation 2011-2015

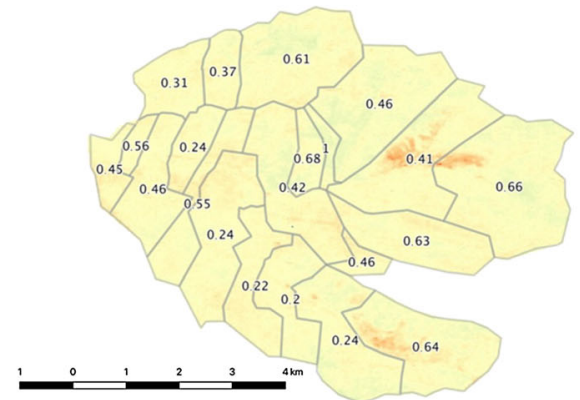

(b) Degradation 2006-2010

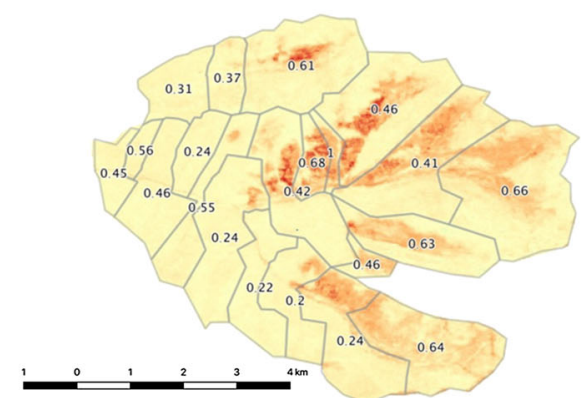

(d) Degradation 2016-2020

Fig. 6 Historical annual maximum NDVI plotting from 1986 to 2019 , comparing the vegetation covers of black-soil areas and pastures that remained resilient. The turning point between the two sets of NDVI values occurred in 2006, the largest disparity was reached in 2016, and differences stabilized thereafter

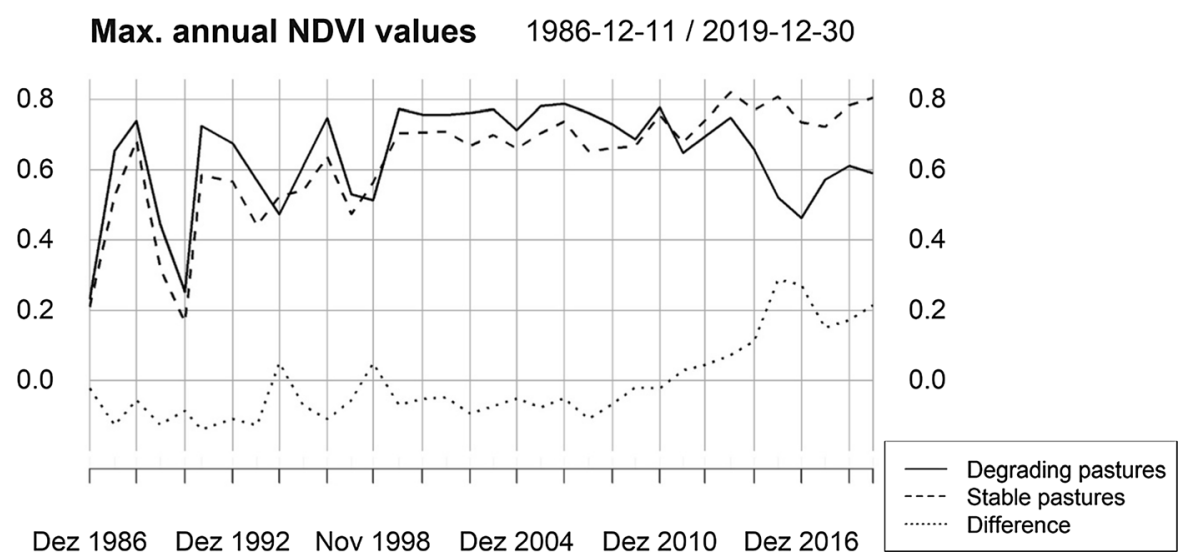

adaptations at the landscape scale. At the beginning, the ecosystem regime shift was locally distributed and affected only a minority of pastures (Fig. 5b), and there were no records of any collective intervention before the regime shift, such as setting a cap on livestock numbers per household to reduce LUI. Pastoralists impacted by the regime shift mostly adapted passively and independently when black-soil areas reached the farm scale. In 2015, we recorded that families affected by black-soil formation were forced to reduce stocking rate (Table 1) due to the declined grassland productivity (Supplementary Fig. S4). In 2018 some black-soil pasture owners still stated that nothing much could be done except renting pastures elsewhere and that restoration was unlikely to help because no village rules can stop neighbors' yak from grazing on my restored pasture, especially during the period of seasonal transhumance. In 2019, however, the village had the first collective discussion regarding the possibility to restore black-soil areas through replantation. It was almost 15 years after the first black-soil patches were detected locally in Karma when the regime shift finally became a concern urgent enough for the village to take actions jointly. 


\section{Discussion}

Spatial features of the SES regime shift: heterogeneity and scale

Using a landscape ecology approach, we examined the spatial dimension of the black-soil formation in the Tibetan rangeland system. Our results show that spatial heterogeneity and scale effects are prominent spatial features of a SES regime shift. In Fig. 7 we summarize the spatial mechanism of the black-soil formation. First, the degradation risk is heterogeneous spatially. The difference between productivity and LUI- used as a proxy for degradation risk-showed an uneven distribution pattern across the landscape, farm and plot scales (Fig. 7a). In our Tibetan grassland case study, degradation didn't first occur where LUI increased the most, but rather pastures of higher degradation risk (Fig. 5). Identifying high-degradation-risk sites at the matching decision-making scale is thus essential for timely adaptive management to avoid undesirable SES regime shifts. Second, regime shifts in SES are a scaled phenomenon. Even if no alternation of stable states has been observed at the landscape scale (Fig. 7a, b), an ecological threshold may have already been crossed at the farm and plot scales (Fig. 7a, c). In our Tibetan grassland case, this scaling-up process of degradation resembled a domino effect of plot-scale black-soil formation taking place one by one in its neighboring plots where degradation risk is relatively high (Fig. 7a). The ecological process can be linked to a growing population of pikas becoming the source population to colonize its nearest sites with suitable condition. This scale effect suggests that early warning signals should be identified at the local scale (at a fine grain). However, when calculated at the landscape scale, variations in LUI and productivity at the farm and plot scales are averaged out (Fig. 7b, c), obscuring the early warning signals, thus undermining timely societal adaptations to ecological changes.

Role of the plateau pika in the black-soil formation

From the ecological perspective, black-soil formation is a complex process in which the foraging, burrowing and dispersal of the plateau pika triggers the formation of black-soil land (Dong et al. 2013; Liu et al. 1999; Shang and Long 2007). This small lagomorph has a home range of approximately $10 \mathrm{~m}$, reproduces up to 5 litters per year (Qu et al. 2013), and it can reach a density of up to approximately 150 individuals/ha (Liu et al. 1999). Based on the vegetation-pika relationship and the spatial expansion pattern detected in our study, we postulate that in the formation of black-soil patches and their expansion, plateau pika drives the self-

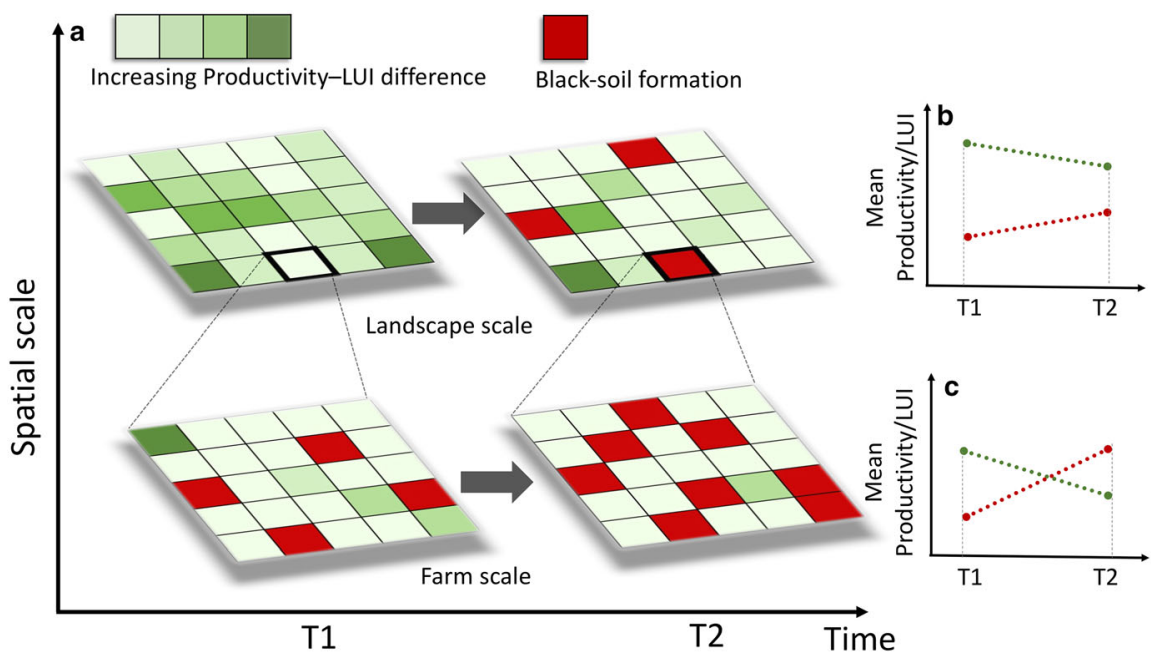

Fig. 7 Spatial model of the black-soil formation as the scaleconnected regime shifts. a Spatial heterogeneity of differences between land-use intensity (LUI) and productivity at the landscape and the farm scale at two time points. At the landscape scale (b), from time point 1 to time point 2, mean LUI (red dashed line) remains lower than productivity (green dashed line), indicating a stable state. However, at the farm scale (c), regime shifts occur between time point 1 and time point 2 after mean LUI surpasses mean productivity 
reinforcing process of the regime shift. At the beginning, intensified livestock grazing in pastures that originally had a high vegetation height (Fig. 8a) reduced above-ground biomass and created local-scale low-vegetation-height plots in the lightly degraded pastures (Fig. 8b), which could then sustain a viable pika population (Fig. 4a, b). Second, when a small pika population inhabited such plots, foraging competition with livestock started due to their considerable overlap in diet (Liu et al. 2008). Third, the colonization by plateau pikas in low-vegetation-height plots further reduced vegetation biomass through foraging and burrowing, increasing the coverage of forbs (Fig. 4c) to form moderately degraded plots (Fig. 8c). The decline of available forage in those moderately degraded plots drove livestock to graze more intensively on the neighboring high-vegetation-height plots, further creating suitable pika habitats and facilitating the spread of the established pika population. Meanwhile, the high-density population of pika continued to cause considerable disturbance to form black-soil areas (Fig. 8d). After the substantial loss of vegetation, the plateau pika population declined due to a lack of resources (Liu et al. 1999) and vegetation succession on the black-soil areas of the pastures continued. This succession ultimately led to dominance of a few pioneer forbs colonizing the black-soil areas in the warm season (Figs. 4d, 8e) which disappear in the cold season, leaving the topsoil at high risk of erosion.

\section{Early warning signals occur at small scales}

Although the tipping point of black-soil formation can be clearly identified by remote sensing time series in retrospect (Figs. 5 and 6), the approach is limited in terms of distinguishing early warning signals from normal annual variations. The early warning signal should be identified timely, i.e., before the SES feedback change starts. Bestelmeyer (2006) argued that a 'degradation threshold' can be too late to regulate the patterns preceding degradation. The ecological threshold is often retrospectively defined when a critical and irreversible transition takes place. Thus, the threshold does not suffice as an early warning signal.

In studying the Tibetan grassland's degradation, we found that there are other earlier important time points
Fig. 8 Photographs showing the stages of the formation of black-soil areas. a Grassland in good condition with grasses and sedges as the dominant species. b Lightly degraded grassland with reduced above-ground biomass, usually caused by intensified land use, creating suitable habitats for plateau pikas. c Increased population of plateau pikas creating moderately degraded grassland, which is usually difficult to restore naturally. d Formation of black-soil areas with a total loss of above-ground vegetation and the sedges' root mat. e Pioneer annual forbs colonizing black-soil areas, making the topsoil prone to water and wind erosion
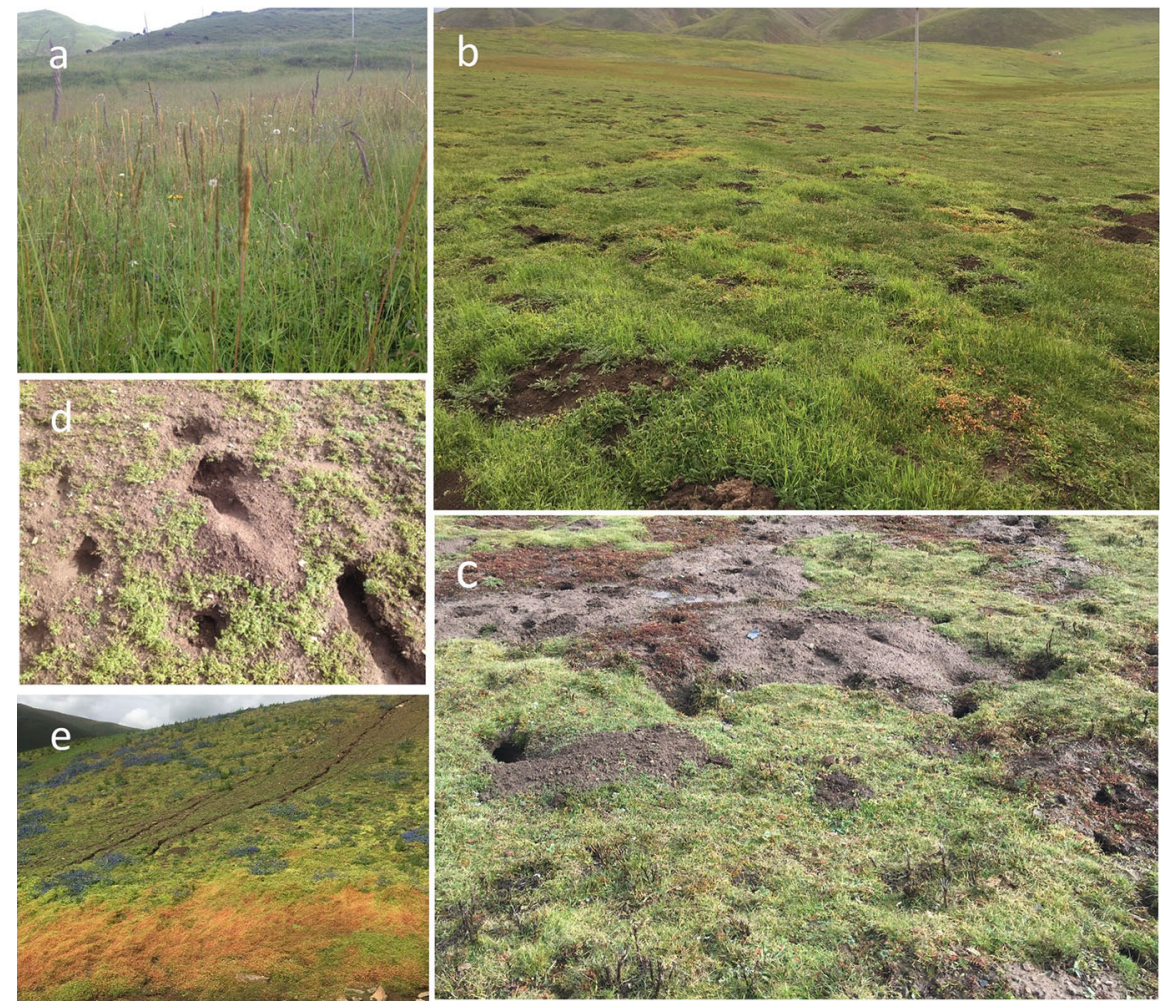
before the tipping point. From the perspective of ecological process, an early-warning time point is when LUI increased, low-vegetation-height habitats had formed locally, and small populations of plateau pikas started to colonize the plots (P2 in Fig. 1). At this stage, a reversal of LUI can still compensate for the loss of productivity to maintain a state of low degradation risk. From the perspective of spatial scale, an early-warning time point is when plot-scale blacksoil patches had formed but farm-scale or landscapescale LUI remained lower than productivity (T1 in Fig. 7).

Noting the ecological process underlying the scaling-up effect of the degradation, we propose that early warning signals should be recognized at small scales, and be jointly considered with farm- or landscapescale features. Taking the Karma village as an example, an early warning signal can be recognized in at least three different ways: 1. The average vegetation height remains taller than $10 \mathrm{~cm}$ (Fig. 4a, b, boxplots with $>20 \%$ vertical coverage), but there are new inhabitations of small populations of pikas to form an increasing number of plot-scale black-soil patches; 2. There is no pika inhabiting the pasture, but the average vegetation height remains lower than $10 \mathrm{~cm}$, and pikas are present in the neighboring pastures; 3 . There are pikas in the pasture, meanwhile there is an increasing coverage of unpalatable forbs especially poisonous weeds at plot scales.

\section{Adaptation time window}

In the Tibetan rangeland SES, the spatial heterogeneity of degradation risk leaves wider or narrower time windows for the social system to avoid the regime shift by adjusting its LUI feedback to the ecological system. However, in the regime shift of Karma neither household-level adaptation of LUI nor communitylevel adaptation to restore black-soil areas happened within the adaptation time window. The first collective intervention attempts to restore degraded grassland were carried out in 2019, when black-soil land became a common concern of the village, i.e., almost 15 years after the black-soil areas were first detected in the village. In our view, the reasons for this unresponsiveness are multi-fold. In theory, LUI consists of three manageable components: number of livestock, pasture size, and duration of pasture use. In Karma, yak rearing remains a form of subsistence agriculture for the majority of households, and alternatives are limited. Herders tend to hold an attitude against slaughter. Traditionally, land-use institutions were in place to regulate the timing of the community's use of rangeland, with movement being the central element of the management. However, the privatization of winter and summer rangelands reduced the mobility of the alpine pastoralism, making management of both the temporal (i.e., foraging time in a pasture) and spatial components (i.e., size of a seasonal pasture) of land-use intensity impossible. At the same time, management of livestock numbers via annual culls is against Buddhist values and traditional pastoral practice.

Therefore, the essential aim of adaptive management is to break such a 'lock-in' situation of their path dependence in land management (Tappeiner et al. 2020; Wilson 2014). Reducing LUI within a limited action period requires finding alternative livelihoods, incorporating novel technologies, making new arrangements in local institutions, or even fostering new local knowledge to change the discourse regarding the cause of the ecological surprise (Hegger et al. 2012). In adaptive management, learning processes usually take place first to advance the knowledge regarding key features and functions of the landscape or the SES (Bürgi et al. 2017). The entry point to initiate such precautionary measures should be started when early warning signals of regime shifts are identified at the local scales. Further, enough time should be left for the land-use decision makers in the social system to complete such an adaptive management circle.

Management implications of the spatial study

Cumming et al. (2006) argued that problems with human society's adaptation to ecological changes may arise because of a mismatch between the scale of management and the scale of ecological processes. In our Tibetan case study, LUI decisions are made at the farm scale under its socio-economic and cultural contexts. However, pika-plant-soil interactions (i.e., the ecological process driving the formation of blacksoil areas) actually function at the plot scale (Dobson et al. 1998; Dong et al. 2013; Wang et al. 2004), which, when related to the plateau pika's population dispersal, also put the neighboring plots, the entire farm, and finally the landscape at risk. This mismatch between 
the farm-scale land-use decision making and the plotscale plateau pika home range occupation challenges flexible societal adaptations to ecological feedbacks. For example, with the use of permanent iron fences to replace herdsmen in Karma, it is impossible to adjust the grazing time of yak herds at a certain spot according to its site-specific vegetation condition anymore. Our results also show that degradation risk is heterogeneously distributed in space. Administrative and local land managers should be made aware that sites of high degradation risk are not necessarily those pastures in low-productivity landscapes. On the contrary, they can be embedded in a relatively lowdegradation risk landscape. However, once the formation of black soil takes place, the local degradation can still be scaled up as a self-organized process if timely management adjustments are not in place.

In China, grassland management administrations have provided a reference 'carrying capacity' value for each region, e.g., 1.0-5.8 sheep unit/ha for the alpine meadows of the Tibetan Plateau, or 1.0-2.2 sheep unit/ha for the desert steppe of Inner Mongolia (Zhang et al. 2014). In our study region, carrying capacity is set only at the scale of the whole Jikdril county as 898,100 sheep unit for all the $6653 \mathrm{~km}^{2}$ usable rangelands (People's Government of Jikdril County 2011). These values are derived based on a regional-scale calculation of productivity and LUI, neglecting the high spatial heterogeneity at the landscape and farm scales. Another drawback of this top-down approach is that the 'carrying capacity' is a newly introduced concept lacking a matching notion in the traditional rangeland management knowledge, which puts time rather than livestock numbers as the goal of management. Moreover, in our interviews Karma pastoralists expressed their reluctance to slaughter livestock due to religious considerations. Wolf et al. (2013) argued that different values or world views of local communities may impede timely adaptations to environmental change. Hence, in the agricultural policy making of Tibetan rangelands, it is necessary to engage local people as part of an effort to enhance joint knowledge production (Hegger et al. 2012). It is important to understand the feasible carrying capacity perceived by the local nomads, taking into account their socio-economic considerations (Nyima 2014), as well as the high spatial heterogeneity shown in our study. Joint experimentation, observation and discussion can be carried out to test different carrying capacities proposed by the locals and by ecologists and to evaluate their different outcomes. Besides, novel solutions need to be developed to enable pastoralists to manage the spatial and temporal dimensions of LUI at small scales.

\section{Conclusions}

In this study, we demonstrate a landscape ecology approach to investigate the spatial dimension of complexity in social-ecological systems. We developed the concept model which analyzes the black-soil formation of the Tibetan rangeland social-ecological system as a regime shift that is triggered by land-use intensification in the past. We demonstrate that the key feedbacks between the social and ecological systems can be conceptualized as land-use intensity, productivity and their difference, and all can be quantitatively measured in space and mapped using approaches developed in landscape ecology. The degradation of Tibetan grassland has remarkable spatial features, as distributions of land-use intensity, productivity and degradation risk are all heterogeneous, and the blacksoil formation can scale up from local plots to the landscape. Our Tibetan rangeland study shows that early warning signals can be identified by understanding the ecological process of the black-soil formation and observing ecologically relevant indications at the local scale, such as the density of plateau pikas, coverage of poisonous weeds etc. However, ecological knowledge regarding the regime shift, social institutions or economic alternatives is not always at hand to facilitate people to find out a path-breaking solution within the limited adaptation time window. The complexity between SES feedbacks can further hinder timely adaptation. For instance, the uneven spatial distributions of degradation risk as well as the legacy effect between land-use intensity change and the black-soil formation may confuse people's perception of causality. The mismatch between the LUI management scale and the scale of the plateau-pika-related ecological process can also cause a delay of adaptation to an early-warning signal until the black-soil areas have expanded to the land-use decision making scales.

Our Tibetan rangeland case study also sheds light on the management of other human-induced environmental changes, such as invasive species, desertification and the encroachment of woody plants in 
grasslands. The finding that ecological regime shifts are strongly linked across spatial scales underlines the importance of detecting local-scale regime shifts and using them as 'entry points' for starting an adaptive management circle. In adapting to ecosystem regime shifts, local knowledge, social institutions and economic alternatives need to be renewed or developed to facilitate the timely re-adjustment of SES feedbacks. Further, important SES features, such as regime shift risks, are heterogenous in space and can only be identified and managed at the local scales. Therefore, the adaptive management circle should start from joint knowledge production by different stakeholders, e.g., integrating ecological and local knowledge to gain new insights regarding the features and functioning of the social-ecological system. The spatially explicit landscape ecological approach can facilitate this learning process and promote adaptive management of SES towards sustainability.

Acknowledgements We thank Shi, $\mathrm{Xu}$ for conducting the pika and vegetation survey. Our friends from the Nyanpo Yutse environmental association provided enormous assistance in the field work. This research was founded by the National Key Research and Development Program of China (No. 2019YFC0507705) and the China Postdoctoral Science Foundation (No. 2019M650322). Melissa Dawes helped with the English language editing of the manuscript.

Open Access This article is licensed under a Creative Commons Attribution 4.0 International License, which permits use, sharing, adaptation, distribution and reproduction in any medium or format, as long as you give appropriate credit to the original author(s) and the source, provide a link to the Creative Commons licence, and indicate if changes were made. The images or other third party material in this article are included in the article's Creative Commons licence, unless indicated otherwise in a credit line to the material. If material is not included in the article's Creative Commons licence and your intended use is not permitted by statutory regulation or exceeds the permitted use, you will need to obtain permission directly from the copyright holder. To view a copy of this licence, visit http://creativecommons.org/licenses/by/4.0/.

\section{References}

Berkes F, Folke C (1998) Linking social and ecological systems for resilience and sustainability. Linking Soc Ecol Syst $1(4): 4$

Berkes F, Colding J, Folke C (2008) Navigating social-ecological systems: building resilience for complexity and change. Cambridge University Press, Cambridge
Bestelmeyer BT (2006) Threshold concepts and their use in rangeland management and restoration: the good, the bad, and the insidious. Restor Ecol 14(3):325-329

Biggs R, Carpenter SR, Brock WA (2009) Turning back from the brink: detecting an impending regime shift in time to avert it. Proc Natl Acad Sci 106(3):826-831

Biggs R, Peterson GD, Rocha JC (2018) The Regime Shifts Database: a framework for analyzing regime shifts in social-ecological systems. Ecol Soc 23:art09

Brown G, Kytta M (2014) Key issues and research priorities for public participation GIS (PPGIS): a synthesis based on empirical research. Appl Geogr 46:122-136

Bürgi M, Humbel A, Li L, Kizos T (2014) Land use intensity is the missing link between actors and biodiversity - conceptual considerations and empirical examples. Linking Biological and Cultural Diversity in Europe: 1st European Conference for the Implementation of the UNESCOSCBD Joint Programme on Biological and Cultural Diversity. Florence, Italy

Bürgi M, Li L, Kizos T (2015) Exploring links between culture and biodiversity: studying land use intensity from the plot to the landscape level. Biodivers Conserv 24(13):3285-3303

Bürgi M, Östlund L, Mladenoff DJ (2016) Legacy effects of human land use: ecosystems as time-lagged systems. Ecosystems 11:1-10

Bürgi M, Ali P, Chowdhury A, Heinimann A, Hett C, Kienast F, Mondal MK, Upreti BR, Verburg PH (2017) Integrated landscape approach: closing the gap between theory and application. Sustainability 9(8):1371

Cumming GS, Cumming DH, Redman CL (2006) Scale mismatches in social-ecological systems: causes, consequences, and solutions. Ecol Soc 11(1):26

Cumming GS, Olsson P, Chapin F, Holling C (2013) Resilience, experimentation, and scale mismatches in social-ecological landscapes. Landsc Ecol 28(6):1139-1150

Dobson FS, Smith AT, Gao WX (1998) Social and ecological influences on dispersal and philopatry in the plateau pika (Ochotona curzoniae). Behav Ecol 9(6):622-635

Dong QM, Zhao XQ, Wu GL, Shi JJ, Ren GH (2013) A review of formation mechanism and restoration measures of "black-soil-type" degraded grassland in the Qinghai-Tibetan Plateau. Environ Earth Sci 70(5):2359-2370

Fagerholm N, Kayhko N, Ndumbaro F, Khamis M (2012) Community stakeholders' knowledge in landscape assessments - mapping indicators for landscape services. Ecol Ind 18:421-433

Folke C, Carpenter S, Walker B, Scheffer M, Elmqvist T, Gunderson L, Holling CS (2004) Regime shifts, resilience, and biodiversity in ecosystem management. Annu Rev Ecol Evol Syst 35:557-581

Folke C, Hahn T, Olsson P, Norberg J (2005) Adaptive governance of social-ecological systems. Annu Rev Environ Resour 30:441-473

Fritz A, Li L, Storch I, Koch B (2018) UAV-derived habitat predictors contribute strongly to understanding avian species-habitat relationships on the Eastern Qinghai-Tibetan Plateau. Remote Sens Ecol Conserv 4(1):53-65

Gagnon CA, Berteaux D (2009) Integrating traditional ecological knowledge and ecological science: a question of scale. Ecol Soc 14(2):59 
Gimmi U, Bürgi M (2007) Using oral history and forest management plans to reconstruct traditional non-timber forest uses in the swiss rhone valley (Valais) since the late nineteenth century. Environ Hist 13(2):211-246

Gorelick N, Hancher M, Dixon M, Ilyushchenko S, Thau D, Moore R (2017) Google Earth Engine: Planetary-scale geospatial analysis for everyone. Remote Sens Environ 202:18-27

Guoluo Overview Editors' Group (2009) Overview of Golok Tibetan Autonomous Prefecture, revised version. Nationality Publisher, Beijing

Harris RB (2010) Rangeland degradation on the Qinghai-Tibetan plateau: a review of the evidence of its magnitude and causes. J Arid Environ 74(1):1-12

Hegger D, Lamers M, Van Zeijl-Rozema A, Dieperink C (2012) Conceptualising joint knowledge production in regional climate change adaptation projects: success conditions and levers for action. Environ Sci Policy 18:52-65

Hopping KA, Yeh ET, Harris RB (2018) Linking people, pixels, and pastures: A multi-method, interdisciplinary investigation of how rangeland management affects vegetation on the Tibetan Plateau. Appl Geogr 94:147-162

Kull CA, Kueffer C, Richardson DM, Vaz AS, Vicente JR, Honrado JP (2018) Using the "regime shift" concept in addressing social-ecological change. Geogr Res 56(1):26-41

Levin S, Xepapadeas T, Crépin A-S, Norberg J, De Zeeuw A, Folke C, Hughes T, Arrow K, Barrett S, Daily G (2013) Social-ecological systems as complex adaptive systems: modeling and policy implications. Environ Dev Econ 18(2):111-132

Li L, Fassnacht FE, Storch I, Bürgi M (2017) Land-use regime shift triggered the recent degradation of alpine pastures in Nyanpo Yutse of the eastern Qinghai-Tibetan Plateau. Landsc Ecol 32(11):2187-2203

Lindenmayer DB, Hobbs RJ, Likens GE, Krebs CJ, Banks SC (2011) Newly discovered landscape traps produce regime shifts in wet forests. Proc Natl Acad Sci USA 108(38):15887-15891

Liu W, Wang Q, Wang X, Zhou L, Li Y, Li F (1999) Ecological process of forming "Black-soil-type" degraded grassland. Acta Agrestia Sinica 7(4):300-307

Liu JG, Dietz T, Carpenter SR, Alberti M, Folke C, Moran E, Pell AN, Deadman P, Kratz T, Lubchenco J, Ostrom E, Ouyang Z, Provencher W, Redman CL, Schneider SH, Taylor WW (2007) Complexity of coupled human and natural systems. Science 317(5844):1513-1516

Liu W, Zhang Y, Wang X, Zhao J, Xu Q, Zhou L (2008) Food selection by plateau pikas in different habitats during plant growing season. Acta Theriologica Sinica 28(4):358-366

Miehe G, Schleuss P-M, Seeber E, Babel W, Biermann T, Braendle M, Chen F, Coners H, Foken T, Gerken T (2019) The Kobresia pygmaea ecosystem of the Tibetan highlands-Origin, functioning and degradation of the world's largest pastoral alpine ecosystem: Kobresia pastures of Tibet. Sci Total Environ 648:754-771

Nyima Y (2014) A larger herd size as a symbol of wealth? The fallacy of the cattle complex theory in Tibetan pastoralism. Area 46(2):186-193

Olsson P, Folke C, Galaz V, Hahn T, Schultz L (2007) Enhancing the fit through adaptive co-management: creating and maintaining bridging functions for matching scales in the Kristianstads Vattenrike Biosphere Reserve, Sweden. Ecol Soc 12(1):83

Ostrom E (2009) A general framework for analyzing sustainability of social-ecological systems. Science 325(5939):419-422

People's Government of Jikdril County (2011) Notification on the implementation protocol of the grassland eco-compensation poliy in Jikdril 2011. Accessed 4 Dec 2020

Pickett ST, Cadenasso ML (1995) Landscape ecology: spatial heterogeneity in ecological systems. Science 269(5222):331-334

Pinto B, Partidario M (2012) The history of the establishment and management philosophies of the Portuguese protected areas: combining written records and oral history. Environ Manage 49(4):788-801

Qu J, Li W, Yang M, Ji W, Zhang Y (2013) Life history of the plateau pika (Ochotona curzoniae) in alpine meadows of the Tibetan Plateau. Mammal Biol 78(1):68-72

Ramankutty N, Coomes OT (2016) Land-use regime shifts: an analytical framework and agenda for future land-use research. Ecol Soc 21(2):51

Santana-Cordero AM, Monteiro-Quintana ML, HernandezCalvento L (2016) Reconstruction of the land uses that led to the termination of an arid coastal dune system: the case of the Guanarteme dune system (Canary Islands, Spain), 1834-2012. Land Use Policy 55:73-85

Scheffer M, Carpenter S, Foley JA, Folke C, Walker B (2001) Catastrophic shifts in ecosystems. Nature 413(6856):591-596

Shang Z, Long R (2007) Formation causes and recovery of the "Black Soil Type" degraded alpine grassland in QinghaiTibetan Plateau. Front Agric China 1(2):197-202

Shang Z, Dong Q, Shi J, Zhou H, Dong S, Shao X, Li S, Wang Y, Ma Y, Ding L, Cao G, Long R (2018) Research progress in recent ten years of ecological restoration for 'black soil land' degraded grassland on Tibetan Plateau - concurrently discuss of ecological restoration in Sanjiangyuan Region. Acta Agrestia Sinica 26(1):1-21

Smith AT, Foggin JM (1999) The plateau pika (Ochotona curzoniae) is a keystone species for biodiversity on the Tibetan plateau. Anim Conserv 2(4):235-240

Song R, Hasagawa N, Li G, Xu N, Cai G, Zhang Q (2008) Botanical composition and grazing behaviour of Qinghai yaks of Plateay type in the natural rangeland. Acta Ecologiae Animalis Domastici 29(5):31-35

Sun F, Chen W, Liu L, Liu W, Lu C, Smith P (2015) The density of active burrows of plateau pika in relation to biomass allocation in the alpine meadow ecosystems of the Tibetan Plateau. Biochem Syst Ecol 58:257-264

Tappeiner U, Leitinger G, Zarina A, Bürgi M (2020) How to consider history in landscpe ecology: patterns, processes, and pathways. Landsc Ecol 943:6

Turner MG (1989) Landscape ecology: the effect of pattern on process. Annu Rev Ecol Syst 20(1):171-197

Wang Y, Wang X, Wang Z, Giraudoux P, Takahashi K, Alastair G (2004) Primary study on habitat choice of plateau pika (Ochotona curzoniae). Sichuan Univ Nat Sci Ed 41:1041-1045

Wang P, Lassoie JP, Morreale SJ, Dong SK (2015) A critical review of socioeconomic and natural factors in ecological 
degradation on the Qinghai-Tibetan Plateau. China Rangeland J 37(1):1-9

Wilson GA (2014) Community resilience: path dependency, lock-in effects and transitional ruptures. J Environ Plan Manage 57(1):1-26

Wolf J, Allice I, Bell T (2013) Values, climate change, and implications for adaptation: evidence from two communities in Labrador, Canada. Glob Environ Change 23(2):548-562

Wu J, Hobbs R (2002) Key issues and research priorities in landscape ecology: an idiosyncratic synthesis. Landsc Ecol 17(4):355-365

Wu X, Zhang X, Dong S, Cai H, Zhao T, Yang W, Jiang R, Shi Y, Shao J (2015) Local perceptions of rangeland degradation and climate change in the pastoral society of Qinghai-Tibetan Plateau. Rangeland J 37(1):11-19
Xiao Y, Xie W, Liang J, Sha Q (1982) Vegetation degradation succession of alpine meadow casued by grazing and its relation with rodent pest. Resour Sci 4(1):76-84

Xin H (2008) A green fervor sweeps the Qinghai-Tibetan Plateau. American Association for the Advancement of Science, Washington

Zhang YJ, Zhang XQ, Wang XY, Liu N, Kan HM (2014) Establishing the carrying capacity of the grasslands of China: a review. Rangeland J 36(1):1-9

Publisher's Note Springer Nature remains neutral with regard to jurisdictional claims in published maps and institutional affiliations. 